\title{
Strategi Manajemen Bencana di Kabupaten Magelang
}

\section{Yunita Arisanti 1*/Putut Wisnu Nugroho 2 ** Health Policy and Politics}

KEBIJAKAN BENCANA DI KAB.MAGELANG SUMBER PENDANAAN KEGIATAN BPBD Kabupaten bencana di Indonesia. Sumber bencana yang ada SUMBER DAYA MANUSIA di BPBD :

yaitu letusan Gunung Merapi, banjir lahar dingin, a. SKPD terkait;

yaitu letusan Gunung Merapi, banjir lahar dingin, a. SKPD terkait;
tanah longsor, dan banjir bandang. Pemerintah b. sumber daya antar daerah;

$\begin{array}{ll}\text { Kabupaten Magelang membentuk Badan } & \text { c. lembaga internasional yang bertugas menangani }\end{array}$

Penanggulangan Bencana Daerah Kabupaten bencana;

Magelang melalui Peraturan Daerah Nomer 3 Tahun d. Search And Rescue (SAR)

Magelang melalui Peraturan Daerah Nomer 3 Tahun d. Search And Rescue (SAR);

2011 tentang Organisasi dan Tata Kerja Badan e. Palang Merah Indonesia (PMI);

Penanggulangan Bencana Daerah. Kebijakan yang f. Perlindungan masyarakat (LINMAS);

lain yaitu Peraturan Daerah Nomer 3 Tahun 2014 g. Lembaga sosial dan keagamaan; dan

tentang Penyelenggaraan Penanggulangan Bencana h. Relawan

di Kabupaten Magelang yang digunakan sebagai Bagaimana strategi meningkatkan peran

pedoman dalam menjalankan program, kebijakan, serta masyarakat sebagai relawan?

penyelenggaraan penanggulangan bencana dan BPBD rutin melakukan sosialisasi kepada masyarakat di

Peraturan Bupati Magelang Nomor 18 Tahun 2016 daerah rawan bencana, pada kesempatan tersebut Tentang Rincian Kegiatan dalam Tahapan masyarakat diberikan pemahaman pentingnya Penyelenggaraan Penanggulangan Bencana pengetahuan kebencanaan. Kemudian pada kesempatan Kabupaten Magelang sebagai pedoman dalam lain dibentuklah relawan tanggap bencana (salah

penyusunan SOP Penanggulangan Bencana di lain dibentuklah relawan tanggap bencana (salah
wilayah Kabupaten Magelang. wilayah Kabupaten Magelang.

FUNGSI BPBD : kebencanaan dan penanganannya agar siap diterjunkan di masyarakat. penanggulangan bencana dari tahap pra bencana, BPBD juga sevcara terjadwal melakukan latihan simulasi saat tanggap darurat dan pasca bencana. Melakukan pengawasan terhadap seluruh tahapan penanggulangan bencana

pelakukan pemantauan dan evaluasi terhadap pelaksanaan Analisis Resiko Bencana

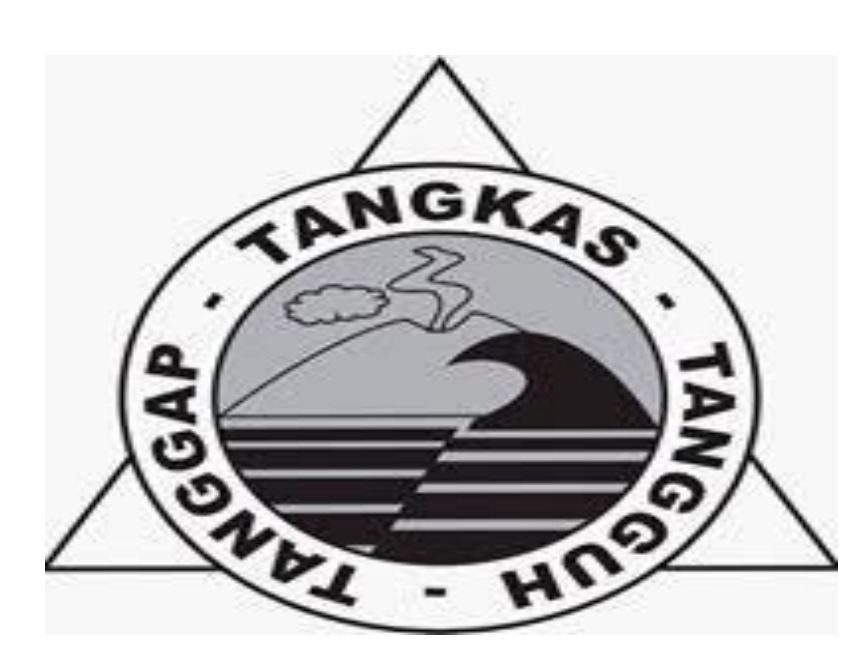

\section{STRATEGI PENANGANAN BENCANA DIKAB} MAGELANG

Membuat kebijakan sebagai pedoman untuk pelaksanaan program

Membuat rencana kegiatan dan tahapan kegiatan dari pra bencana, tanggap darurat sampai pasca

3. Menyusun SOP penanganan bencana

4. Melakukan Analisiis Risiko Bencana dan membua peta resiko rawan bencana

. Melakukan inovasi kegiatan dengan memberdayakan masyarakat melibatkan kalangan disabilitas, lansia dan anak anak salah satunya Latihan dasar Penyelamatan, Evakuasi dan Penanganan pengungsi untuk taruna tangga bencana, sekolah siaga bencana, simulasi longso di kawasan rawan bencana longsor.

6. Menggunakan media sosial seperti Twitter Instagram, FB sebagai salah satu sarana sosialisas kebencanaan

7. Sosialisasi dengan lintas sektor yaitu TNI, POLRI dan BMKG, BPPTKG

8. Menggunakan teknologi berdaya guna seperti EWS Sederhana untuk pantau longsor
GAMBAR KEGIATAN BPBD
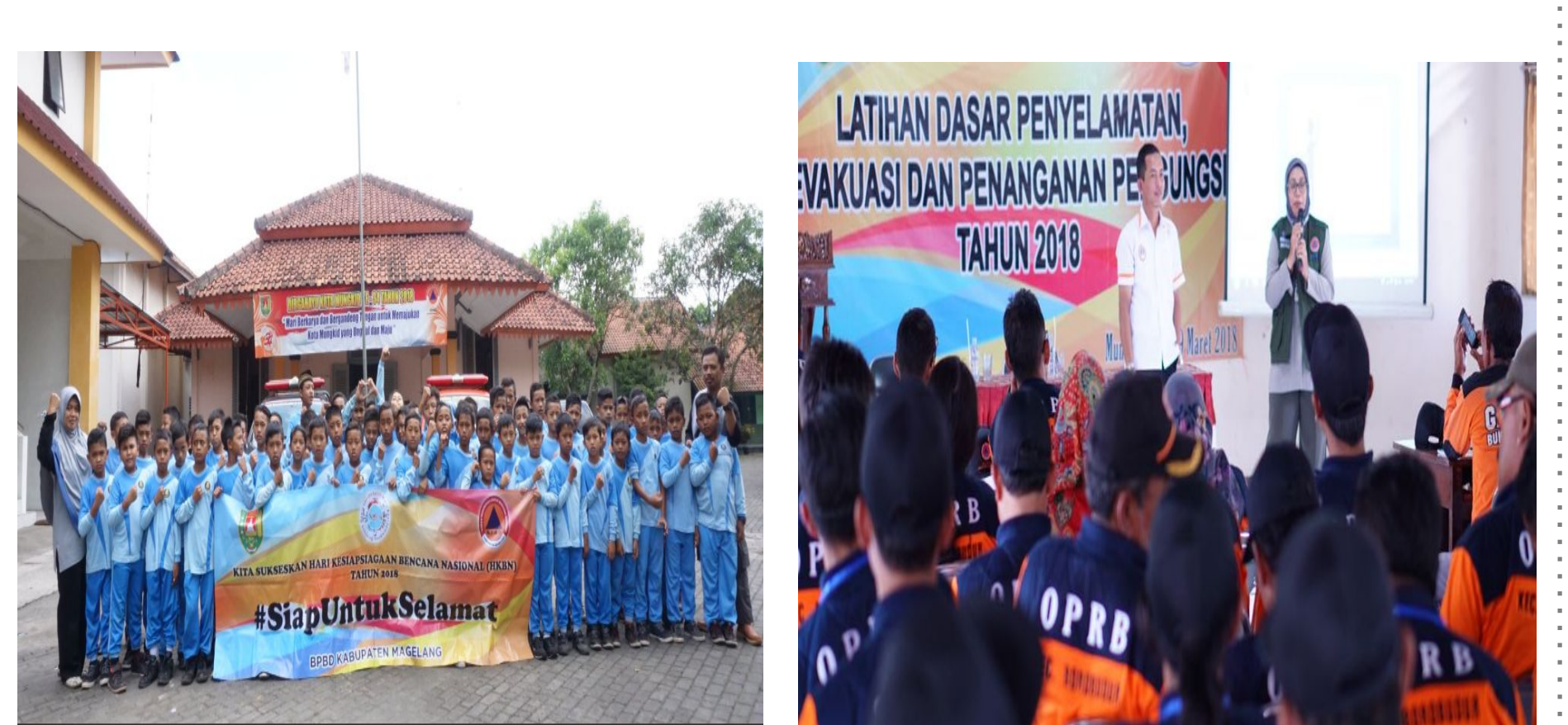

KESIMPULAN

Keberhasilan menerapkan Peraturan Daerah menjadikan Kabupaten Magelang pada tahun 2018 mendapat penghargaan BNPB untuk kategori BPBD terbaik peringkat II wilayah satu dalam penanggulangan bencana di wilayah Kabupaten Magelang dengan pertimbangan sistem manajemen, pelaporan dan penanganan yang cepat terhadap wilayah yang terdampak bencan

SARAN

Untuk lebih meningkatkan kualitas penanganan bencana

kami memberikan saran :

. Membuat/memeperbaiki jalur evakuasi di lokasi rawan bencana,

b. membentuk tim penanggulangan resiko bencana di tiap desa yang rawan bencana,

c. mengembangkan Puskesmas Disaster Plan (tim medis reaksi cepat)

d. menerapkan strategi penanggulangan bencana yang berbeda di setiap lokasi dengan sumber bencana yang berbeda pula.

REFERENSI

Peraturan Daerah Kabupaten Magelang Nomer 3 Tahun $2014 \quad$ tentang Penanggulangan Bencana di Kabupaten Magelang https://twitter.com/bpbdmagelang?lang=en

Sudibyakto,H.A, Manajemen Bencana Indonesia ke mana?, UGM Press, 2018

Budi HH, Setio, Komunikasi Bencana: Aspek Sistem (Koordinasi, Informasi dan Kerjasama), Jurnal ASPIKOM Vol 1, No 4, 2012

Handayani, Riny, Analisis Partisipasi Masyarakat dan Peran Pemerintah Daerah dalam Pelaksanaan Manajemen Bencana di Kab Serang Provinsi Banten, lab-ane.fisip-untirta.ac.id, 2011 